\section{Association between Root Caries and Depressive Symptoms among Elders in Carlos Barbosa, RS, Brazil}

Otávio Pereira D'Avila', Eliana Wendland², Juliana Balbinot Hilgert', Dalva

Maria Pereira Padilha ${ }^{1}$, Fernando Neves Hugo ${ }^{1}$
'Research Center for Social and Preventive Dentistry, Dental School, UFRGS - Universidade Federal do Rio Grande do Sul, Porto Alegre, RS, Brazil ${ }^{2}$ Department of Public Health, UFCSPA - Universidade Federal de Ciências da Saúde de Porto Alegre, Porto Alegre, RS, Brazil

Correspondence: Otávio Pereira D’Avila, Ramiro Barcelos, 2492, 90035-003 Porto Alegre, Brasil. Tel: +55-51-3308-5010. E-mail: otaviopereiradavila@gmail.com

Key Words: root caries, aging, depression symptoms, epidemiology, oral health.

\section{Introduction}

Because of global population aging, various authors have been dedicated to study health and disease issues in this population, especially oral health. This area of research has become more relevant due to changes in the age distribution, the rise of life expectancy that occurred in many countries and the burden of oral diseases in this age group (1). In addition, poor oral health is linked to common diseases in this age group, like diabetes mellitus, coronary disease, respiratory problems and mental health (1). Another important morbidity of relevance for older people is depression. Its prevalence in older people varies between $8 \%$ and $10 \%$ (2). However, its association with oral health status has not been thoroughly evaluated yet. There are few studies showing that depressive disorders may influence oral health outcomes, by negative effects in the immunological system, lack of motivation, dietary changes and smoking $(3,4)$.

Epidemiological studies in older people have shown that edentulism, periodontal disease, and coronal and root caries are the most prevalent oral health outcomes in this population $(5,6)$. The scientific community has already demonstrated the importance of identifying multiple determinants in oral health, operating through social, behavioral, psychological and biological factors (7).

Root caries prevalence varies between $39 \%$ and $47 \%$ among older people and its association with multiple factors reinforces the need for epidemiological studies (5). The role of psychological suffering on immunity and oral health-related behavior is recognized. However, only one study has investigated the relationship between depressive symptoms and root caries in older people (8). Nevertheless, according to the referred authors, depressive symptoms were not featured in the final prediction model and were not associated with root caries.

Some studies investigated the association between psychological variables (stress and anxiety) and oral diseases $(4,9,10)$. The association between stress and depression with oral health may be explained by behavioral alterations, like less efficient oral hygiene and/or a reduction in the frequency of oral hygiene during the stress or psychiatric disease and change in tobacco and dietary habits (11). Antilla et al. (9) found an association between depressive symptoms and edentulism. Worse oral health behavior was also linked to depression, a finding that was verified by 
a decrease in tooth brushing frequency and visits to the dentist (10). However, previous evidence suggested that the psychosocial factors might alter susceptibility, indirectly by affecting health behavior and directly by changes in the host response (11).

Depression may be associated to root caries by two mechanisms. The psychosocial explanation of the social determinants of health proposes the depression to act through changes in self-care behaviors and attitudes (i.e. worse hygiene and less frequent consultations) and by changes that may occur in the immune system due to psychological suffering (12). There is evidence, which suggests that stress and depression are associated with high plaque levels and gingivitis, whereas psychological distress is negatively associated with salivary secretory immunity (13). Both findings confirm the plausibility of the association between depression and root caries, warranting the assessment of this study hypothesis. The aim of this study was to evaluate the association between depressive symptoms and root caries in older independent-living people in Carlos Barbosa, RS, Brazil.

\section{Material and Methods}

\section{Study Design and Context}

This cross-sectional study was based on data collected by a larger study about oral health, quality of life and depressive symptoms in independently living older people, carried out during 2004/2005 in the city of Carlos Barbosa, in Southern Brazil. Carlos Barbosa is a city located in Rio Grande do Sul state, in the southern region of Brazil. The town is located $104 \mathrm{~km}$ north of Porto Alegre, the State capital, with a population composed mainly by people of European ancestry. The city had 20,519 inhabitants in 2000 and among them, 2,177 were aged 60 years or more, according to the Brazilian census of 2000. In addition, $74.5 \%$ of the households had fluoridated water and the remaining $25.5 \%$ were supplied by untreated drinking water from community wells.

\section{Sampling}

A simple random sampling design was used and the required sample size was estimated based on the outcome of coronal caries from a calculation composed of the prevalence of caries among non-depressed and depressed patients. This endpoint was used because it was the main purpose of the study and generated a larger sample size than the one calculated for the study of root caries, so that the latter estimate is more frequent (15). This calculation led to a sample of 202 individuals per group, giving a total of 404 participants in the study.

Only persons aged 60 years or more, living independently and with good general health were invited to take part in the study. Generally healthy persons were defined as persons whose physical, medical and mental status allowed them to undertake travel to participate in a comprehensive oral health examination in a clinical setting.

The participants were selected following simple random sampling strategy from the municipality register of persons aged 60 years or more. The subjects were contacted by telephone and invited to participate in the study. Out of the 872 persons who agreed to take part, 785 completed the protocol (i.e. older persons for whom questionnaires and oral examination information were available), where 390 had at least one tooth and were evaluated in the present study. Inclusion and exclusion criteria were already described elsewhere (15).

In order to verify whether the study participants were representative, socio-economical data were retrieved from municipality records, considering the older people that lived in the city. There were no significant differences in age, sex or location of residence between the study participants and the overall population living in Carlos Barbosa (15).

The study was developed after appreciation and approval by the Research Ethics Committee of the Piracicaba Dental School, UNICAMP, in accordance with the Declaration of Helsinki.

\section{Socio-Demographic Variables}

Employing a standardized questionnaire, the participants were asked about age, gender, income, schooling, geographic location and marital status. Age was measured in years. The geographical location of the participant's residence was categorized as urban or rural, location being used as a proxy for access to fluoridated water, as $97.7 \%$ of the inhabitants of Carlos Barbosa living in an urban area and $8.1 \%$ of the inhabitants living in a rural area were supplied fluoridated water. For the analysis, the individual monthly income was categorized as $\geq 1$ minimum wage or $\leq 1$ minimum wage (i.e. ' $1>$ BRL 260.00 'or ' $\leq$ BRL 260.00', with BRL 260.00 equivalent to 1 minimum wage, or 83 USD, during the data collection period). Monthly income was categorized using the median split. Marital status was categorized as single, married, divorced or widowed. Schooling was categorized in three groups: four or less study years, between five and eight study years, or more than eight study years.

\section{Behavioral Variables}

Using a standardized questionnaire, the participants were asked about tobacco consumption, frequency of oral hygiene, use of medications and self-reported medical history. Smoking status was dichotomized into non-smoker/ former smoker or current smoker; the frequency of tooth brushing was defined as brushing less than twice a week, 
brushing one or two times a day, or brushing more than two times a day. The participants were invited to inform how many medications they used and whether they were prescribed by a physician. The number of prescribed medications used by each participant was analyzed as a continuous variable. If a participant was not sure about all the prescriptions he/she was taking, he/she was asked to check and take note of the prescriptions at home and was informed by the research assistant that she would call them at home to check the information with respect to medication intake. The number of prescribed medications used by each participant was obtained based on this information and subsequently categorized into ' $0-1$ medication' or ' $\geq 2$ medications'. The self-reported medical history involved 19 diseases including cancer, hypertension, diabetes, kidney disease, and cardiorespiratory disease, among others. The participants were asked whether in previous physician visits, the physician had mentioned any of the conditions above. These conditions were dichotomized into presence of no or one disease (absence of co-morbidity), or presence of two or more diseases (presence of co-morbidity).

\section{Evaluation of Depressive Symptoms}

Depressive symptoms were evaluated by the GDS (Geriatric Depression Scale), originally developed by Yesavage et al. (16). In the current study, the data were obtained by a reduced version validated in Brazil (GDS - 15), which results in valid measures for the diagnosis of recurrent depressive disorder according to ICD-10 (International Statistical Classification of Diseases and Related Health Problems, 10th Edition) and DSM-IV (Diagnostic and Statistical Manual of Mental Disorders, 4th Edition).

\section{Oral Examinations}

Oral examinations were carried out in dental clinics in the Public Health Services provided by the municipality, in standardized conditions. Two previously trained experienced dentists carried out all examinations. The plaque index and the gingival bleeding index were evaluated in six sites per tooth. All teeth were evaluated and the resulting score was presence or absence of plaque in all evaluated sites. The plaque examinations and the assessment of gingival bleeding were made with an air syringe, artificial light, odontoscope and periodontal probe. Mean plaque and gingivitis indexes were calculated for each participant. The root condition was evaluated using the Decayed Filled Root (DF-R) index, according to the WHO criterion (18). All teeth were evaluated, including third molars.

Unstimulated whole saliva was collected through the spit method, as described by Navazesh and Christensen (19). The unstimulated saliva flow was expressed in $\mathrm{mL}$ per $5 \mathrm{~min}$.

\section{Outcome}

The outcome was the ratio of the number of teeth with root cavities to the total teeth with roots at risk (teeth that had gingival recession). The criteria for diagnosis of caries followed the DMFT-root index. In addition, the interaction between depressive symptoms and gender was tested, given its scientific plausibility.

\section{Statistical Analysis}

Inter and intra examiner reliability was calculated for the DMFT-r index and plaque index assessments using Kappa statistics. In order to evaluate the internal consistency of GDS, Cronbach's alpha coefficient was also calculated. A detailed description of the examiners' training and quality control of the examinations was reported elsewhere (15).

The association between depressive symptoms and root caries was investigated using robust and adjusted regression models. The Poisson regression model, generally used to model counting data, was shown as inappropriate due to overdispersion (the ratio of the deviance to the degrees of freedom was greater than one). Therefore, an alternative negative binomial distribution was selected, able to look at the behavior of overdispersed data. The independent variables were initially tested in bivariate models. Variables with $p<0.20$ were included in the multivariate models. The adequacy of the model was verified by assessing the ratio of deviance to the degrees of freedom of the model, or the dispersion parameter, so that a parameter value close to zero indicates that the model would be similar to a Poisson regression model. Analyses were performed using SAS version 9.2 software.

\section{Results}

The Kappa coefficient for intra and inter examiner reliability for the DMFT assessments before and during the study varied between 0.98 and 1.00. The Kappa coefficient for intra and inter examiner reliability for the plaque index evaluation varied between 0.7 and 0.84 . The Cronbach's alpha coefficient for the GDS was 0.77 .

Approximately half of the sample was male (51.3\%) and the mean age was $66.87( \pm 6.1)$ years (Table 1). Most were married (80\%), lived in an urban area $(52.7 \%)$, had an individual income equal or less than one minimum wage $(52.3 \%)$ and had up to four years of study (36.5\%); $72.5 \%$ of them said they did not smoke. In relation to oral hygiene behavior, $33 \%$ of the interviewees said that they brushed their teeth more than twice a day. The prevalence of root caries in the studied population was 74.2\% $(n=288)$. The mean of the root caries/roots at risk ratio was $0.26( \pm 0.27)$. The prevalence of depressive symptoms was $10.8 \%$, or 41 individuals. The mean percentage of sites with visible plaque was $67.8 \%( \pm 2.8)$ and the mean 
gingival bleeding was $57.4 \%( \pm 2.8)$.

Table 2 and Table 3 present the bivariate analysis for

Table 1. Characteristics of the sample

\begin{tabular}{|c|c|c|}
\hline Variable & Description & $\mathrm{N}(\%) /$ Average $( \pm \mathrm{sd})$ \\
\hline Sex & Female & $190(48.7 \%)$ \\
\hline Age & In years & $66.87( \pm 6.1)$ \\
\hline Area & Urban & $206(52.7 \%)$ \\
\hline \multirow{4}{*}{ Marital Status } & Single & $7(1.8 \%)$ \\
\hline & Married & $312(80 \%)$ \\
\hline & Divorced & $8(2.1 \%)$ \\
\hline & Widowed & $63(16.2 \%)$ \\
\hline \multirow{3}{*}{ Schooling } & $\leq$ four years of study & $275(70.7 \%)$ \\
\hline & $\leq$ eight years of study & $95(24.4 \%)$ \\
\hline & > eight years of study & $19(4.9 \%)$ \\
\hline Income & $\geq$ minimum wage & $204(52.3 \%)$ \\
\hline \multirow[t]{2}{*}{ Smoke } & Yes & $33(27.5 \%)$ \\
\hline & $<2 \mathrm{x} /$ week & $37(9.5 \%)$ \\
\hline \multirow[t]{2}{*}{ Toothbrushing frequency } & 1 or $2 \mathrm{X} /$ day & $225(57.5 \%)$ \\
\hline & $>2$ X/day & $129(33 \%)$ \\
\hline Depressive symptoms & Absent & $338(89.2 \%)$ \\
\hline Plaque index & $\%$ of sites & $67.58 \%( \pm 2.8)$ \\
\hline Gingival bleeding index & $\%$ of sites & $57.54 \%( \pm 2.8)$ \\
\hline Rest saliva flow & $\mathrm{ml} / 5 \mathrm{~min}$ & $0.86( \pm 0.7)$ \\
\hline Quantity of medications/day & & $1.89( \pm 1.9)$ \\
\hline Root caries/Root at risk & & $0.26( \pm 0.27)$ \\
\hline
\end{tabular}

socio-economical and health behavior variables in relation to the outcome. The socio-economical and health behavior variables of age, living in a rural area, females, lower income, smoking and tooth brushing frequency showed had $p>0.20$ and were included in the multivariate model. The psychological variable of depressive symptoms, although it showed a high p value, was included in the multivariate model due to its epidemiological and clinical relevance. The oral ecology variables of plaque index, gingival bleeding index, saliva flow at rest and self-perception of oral health were also included in the multivariate model.

In the multivariate analysis (Table 4), the binominal regression revealed in its final model that age $(\beta=0.03 ; p=0.001)$, living in a rural area $(\beta=0.25 ; p=0.025)$, tooth brushing frequency ( $<$ twice a week) $(\beta=0.43 ; p<0.018)$, saliva at rest flow $(\beta=-0.012 ; p<0.000)$ and the interaction between gender and depressive symptoms $(\beta=-0.099 ; \quad p<0.001)$ were significantly associated with the root caries/root at risk ratio. The association of the interaction with the outcome meant that males with depressive symptoms were at increased risk for the outcome, since the negative signal for $\beta$ represents females with no depressive symptoms.

Table 2. Bivariate analysis of the association between the studied socio-demographical variables and the outcome of the study

\begin{tabular}{|c|c|c|c|c|c|c|c|}
\hline Variable & Description & $\mathrm{N}$ & freq & Beta & SE & $95 \%$ & $\mathrm{p}$ \\
\hline Age & Age & 390 & & 0.02 & 0.008 & $0.04-0.037$ & 0.013 \\
\hline Sex & $\begin{array}{c}\text { Female } \\
\text { Male }\end{array}$ & $\begin{array}{l}190 \\
200\end{array}$ & $\begin{array}{l}48.7 \\
51.3\end{array}$ & 0.15 & 0.107 & $-0.06-0.36$ & 0.166 \\
\hline \multirow{2}{*}{ Area } & Urban & 206 & 52.7 & & & & \\
\hline & Rural & 185 & 47.31 & -0.1779 & 0.1071 & $-0.39-0.032$ & 0.096 \\
\hline \multirow{2}{*}{ Income } & ( $\leq 1$ minimum wage) & 204 & 52.31 & 0.28 & 0.108 & $0.07-0.49$ & 0.009 \\
\hline & ( $\geq 1$ minimum wage) & 186 & 47.69 & & & & \\
\hline \multirow{4}{*}{ Marital Status } & Single & 7 & 1.8 & & & & \\
\hline & Married & 312 & 79.8 & -0.05 & 0.467 & $-0.97-0.87$ & 0.919 \\
\hline & Divorced & 8 & 2.0 & -0.13 & 0.615 & $-1.33-1.08$ & 0.836 \\
\hline & Widowed & 63 & 16.11 & 0.13 & 0.480 & $-0.81-1.1$ & 0.780 \\
\hline \multirow{3}{*}{ Schooling } & $\leq 4$ years of study & 275 & 70.7 & & & & \\
\hline & $\leq 8$ years of study & 95 & 24.4 & -0.03 & 0.121 & $-0.27-0.21$ & 0.795 \\
\hline & $>8$ years of study & 19 & 4.9 & 0.06 & 0.242 & $-0.41-0.54$ & 0.791 \\
\hline
\end{tabular}




\section{Discussion}

In the current study, socio-economical variables, including age and living in a rural area, health behavior

Table 3. Bivariate Analysis. Association between behavioral, psychological, biological, and perceptive variables, studied in the outcome.

\begin{tabular}{|c|c|c|c|c|c|c|}
\hline Variable & Description & $\mathrm{N}$ & Freq & Beta & $95 \%$ & $\mathrm{p}$ value \\
\hline \multirow{2}{*}{ Smoke } & Yes & 33 & $8.44 \%$ & 0.89 & $0.5-1.2$ & $<0.001$ \\
\hline & No & 87 & $22.25 \%$ & & & \\
\hline \multirow{3}{*}{$\begin{array}{l}\text { Tooth brushing } \\
\text { frequency }\end{array}$} & $<2 \mathrm{x} /$ week & 37 & $9.46 \%$ & & & \\
\hline & 1 or $2 x /$ day & 225 & $57.54 \%$ & -0.38 & $-0.71-0.04$ & 0.027 \\
\hline & $>2 x /$ day & 129 & $32.99 \%$ & -0.45 & $-0.81-0.09$ & 0.014 \\
\hline Quantity & & & & 0.018 & $-0.04-0.07$ & 0.5369 \\
\hline \multirow{2}{*}{ Comorbidity } & Absent & 205 & $52.43 \%$ & 0.01 & $-0.19-0.22$ & 0.8991 \\
\hline & Present & 186 & $47.57 \%$ & & & \\
\hline \multirow{2}{*}{ Depression } & Absent & 338 & $89.18 \%$ & -0.002 & $-0.34-0.33$ & 0.991 \\
\hline & Present & 41 & $10.82 \%$ & & & \\
\hline \multirow{5}{*}{$\begin{array}{l}\text { Perception of } \\
\text { the oral health }\end{array}$} & Excellent & 9 & & & & \\
\hline & Very good & 26 & $6.65 \%$ & 0.77 & $-0.20-1.74$ & 0.122 \\
\hline & Good & 211 & $53.96 \%$ & 0.39 & $-0.49-1.29$ & 0.381 \\
\hline & Reasonable & 133 & $34.02 \%$ & 0.74 & $-0.15-1.63$ & 0.103 \\
\hline & Bad & 12 & $3.07 \%$ & 0.7478 & $-0.24-1.74$ & 0.140 \\
\hline Saliva & Unstimulated & & & -0.018 & $-0.02-0.01$ & $<.0001$ \\
\hline Plaque index & \% Sites & & & 0.011 & $0.01-0.01$ & $<.0001$ \\
\hline $\begin{array}{l}\text { Gingival } \\
\text { bleeding index }\end{array}$ & \% Sites & & & 0,011 & $0,01-0,01$ & $<0,001$ \\
\hline
\end{tabular}

Table 4. Final model totally adjusted to the studied variables associated with the outcome

\begin{tabular}{|c|c|c|c|c|c|}
\hline Variables & Description & Beta & $\begin{array}{c}\text { Pattern } \\
\text { deviation }\end{array}$ & $\begin{array}{c}\text { Confidence } \\
\text { interval }\end{array}$ & $p$ value \\
\hline Age & In years & 0.03 & 0.0086 & $0.01-0.04$ & 0.001 \\
\hline Sex & Female & -0.23 & 0.1330 & $-0.49-0.02$ & 0.08 \\
\hline Area & Rural & 0.25 & 0.1135 & $0.03-0.47$ & 0.025 \\
\hline Income & $\begin{array}{l}\text { Less than } 1 \\
\text { minimum wage }\end{array}$ & -0.15 & 0.1183 & $-0.38-0.08$ & 0.204 \\
\hline \multirow{3}{*}{$\begin{array}{l}\text { Toothbrushing } \\
\text { frequency }\end{array}$} & $<2 \mathrm{x} /$ week & 0.43 & 0.1813 & $0.07-0.78$ & 0.018 \\
\hline & 1 or $2 x /$ day & 0.02 & 0.1312 & $-0.23-0.27$ & 0.891 \\
\hline & $>2 x /$ day & 0.000 & 0.000 & $0.00-0.00$ & . \\
\hline Saliva & $\begin{array}{l}\text { Unstimulated } \\
\text { saliva }\end{array}$ & -0.012 & 0.1183 & $-0.38-0.01$ & $<.0001$ \\
\hline $\begin{array}{l}\text { Interaction } \\
\text { between gender } \\
\text { and depression }\end{array}$ & $\begin{array}{l}\text { Females and } \\
\text { absence of } \\
\text { depression }\end{array}$ & -0.99 & 0.3960 & $-1.77-0.21$ & 0.012 \\
\hline
\end{tabular}

variables, specifically tooth brushing frequency ( $\leq$ twice a week) and an oral ecology variable, saliva flow, were independently associated with root caries. In addition, the interaction between the presence of depressive symptoms and the male ender was associated with the studied outcome. This means that older men with depressive symptoms were more likely to have more caries than either older men without depressive symptoms or women. Such finding confirms the hypothesis that psychological suffering, at least among men, may be associated with root caries, which is in accordance with the theoretical framework of caries in populations proposed by Holst et al (20). Depression symptoms may lead to changes in saliva flow (21) and immunity (22) and worsen health behaviors (4), favoring root caries development. This is one of the first studies that confirms the importance of psychological reactions to root caries among older people. Different mechanisms have been proposed to explain the significance of psychological suffering in the development of oral diseases, including an action intermediated by the effects of changes in health behavior due to depression and a direct action via the immunosuppression caused by the psychological disorders, such as depression and chronic stress with direct effects in the salivary innate immunity $(4,10,21)$.

Among the behavior changes related to depression, modifications in the dietary habits, tooth brushing frequency and change in the visit pattern to the dentist have been mentioned in previous studies $(10,13)$. Such findings suggest that behavior changes and worse health selfcare would be the ways by which the psychological suffering interferes in the development of dental caries (23). Furthermore, the human immune system may undergo important modifications after a psychological event like depression. In such cases, the hypothalamic-pituitaryadrenal axis is hyper-activated and stimulates an increase of cortisol secretion (22). The cortisol decreases the number of lymphocytes and circulating neutrophils. These cells act in the protection of the oral cavity attached to the saliva proteins that have bactericidal 
and bacteriostatic roles (24). Despite this evidence, few studies have investigated the association between caries and depressive symptoms. In a study on the prevalence of depressive symptoms in an elderly population, Hugo et al. (25) found an association between depressive symptoms and coronal caries.

One of the mechanisms by which depression can act in men's oral health is related to changes in their health behavior. Holst et al. (20) proposed a conceptual structure of dental caries, which postulates that psychological reactions interfere indirectly with dental caries. The present study findings confirm this model, even when taking into account the limitations of the analytical strategy.

According to Aleksejunie et al. (26), oral health behavior and the pattern of visits to the dentist have a more proximal effect on a negative oral health outcome in men than in women. However, depressive symptoms are also associated with worse health behavior. Antilla et al. (10) observed that male patients with depressive symptoms had a worse pattern of self-care behavior than those without such symptoms. Furthermore, these authors also observed that men with depression displayed high salivary lactobacilli counts compared with women. Although depression and male sex have not been independently associated with root caries, the interaction between these two variables seems to have a significant influence in the development of root caries in the studied population. It may be speculated that this interaction may reinforce worse health behavior among men, which in turn favors a negative oral health outcome.

The geographical location of the participants' residence (Carlos Barbosa city) represents a proxy to access to fluoridated water. The study findings suggest that living in rural area, where the access to fluoridated water is practically inexistent, is associated with root caries. However, few studies of root caries prevalence have investigated an association between the geographical location of the individuals' residence and the presence of root caries (6). In the context of the studied population, living in a rural area means that there is no access to this facility, the effectiveness of which is confirmed by several previous studies (20).

Saliva has a recognized role in the protection of dental sites. Besides helping in the cleaning of teeth, it is responsible for homeostasis of the oral cavity, preventing the decrease of the local $\mathrm{pH}$ and formation of a propitious means for the development of caries (20). Beyond this, few population studies have shown this role of saliva.

The presence of tooth brushing has an important role in the biofilm disorganization and re-mineralization of the dental tissue and can explain the appearance of new episodes of root caries (5). The results of the current study that low tooth brushing frequency, i.e. less than once a day, has shown to be associated with the studied outcome.
To the best of authors' knowledge, this is one of the first studies indicating an association between depression and root caries. In the only previous study found, there was an independent and not significant association between caries and depression. Sanchez-Garcia et al. (27) studied a predictive model for root caries in older people, which included biological and behavioral variables, but the variable depression was not included in the final model.

Some limitations must be considered when interpreting the results of the current study. First, data interpretation is subject to the effects of reverse causality due to the crosssectional design of the study. Furthermore, professional plaque removal was not performed during oral examinations, which probably led to an underestimation of the diagnosis of root caries lesions.

The present findings suggest that depressive symptoms may be significant predictors of root caries in older men, if incorporate these additional findings alongside the existing evidence for the importance of psychological suffering as a determinant of oral health outcome. Further studies are required in order to elucidate these mechanisms, including behavior and psychoneuroimmunology factors, whether the effect is confirmed in other age groups and whether these factors are direct or intermediated by other proximal variables.

\section{Resumo}

0 objetivo deste estudo foi avaliar a associação entre sintomas depressivos e cáries radiculares entre idosos independentes. Todos os idosos moradores da comunidade (não hospitalizados e não acamados) residentes em Carlos Barbosa, RS, foram convidados a participar, e 785 completaram o protocolo do estudo (questionário padronizado de avaliação sociodemográfica e comportamento de saúde, Escala de Depressão Geriátrica [GDS ] - versão resumida e exame oral [índice de CPOD-Raiz, índice de placa visivel e fluxo salivar estimulado]). Destes, 390 participantes com pelo menos um dente natural foram incluídos na presente análise. 0 desfecho foi a razão entre o número de raízes em decomposição e o número de raízes em risco. A associação entre variáveis independentes (depressão e aspectos socioeconômicos) e o desfecho foram avaliados utilizando modelos de regressão binomial negativa. 0 modelo final totalmente ajustado revelou que a idade $(\beta=0,03, p=0,001)$, sexo feminino $(\beta=-0,23, p=0,08)$, vivendo em área rural $(\beta=0,25, p=0,008)$, frequência de escovação $(\beta=0,43$, $p=0,025)$ e o fluxo salivar estimulado $(\beta=-0,012, p<0,0001)$ foram significativamente associados à presença de cárie radicular. Além disso, a interação entre sexo masculino e a presença de sintomas de depressão ( $\beta=-$ $0,99, p=0,012$ ) também foi independente e significativamente associada com cáries radiculares. $A$ interação entre sexo masculino e sintomas de depressão foi associada com cárie radicular, sugerindo que mecanismos psicológicos podem estar envolvidos indiretamente no desenvolvimento de cáries radiculares em adultos mais velhos.

\section{Acknowledgements}

This study received financial support from the Brazilian National Council for Scientific and Technological Development (CNPq).

\section{References}

1. Petersen $P E$, Yamamoto T. Improving the oral health of older people: 
the approach of the WHO Global Oral Health Programme. Community Dentistry and Oral Epidemiology. 2005;33:81-92.

2. Sonowdon J. How high is the prevalence of depression in old age? Rev Bras Psiquiatr 2002;24(Suppl 1):42-47.

3. Anttila SS. Depressive symptoms in relation to oral health and related factors in a middle-aged population: analytical approach [dissertation]. Oulu, Finland: University of Oulu;2003.

4. Hugo FN, Hilgert JB, Bozzeti MC, Bandeira DR, Gonçalves TR, Pawlowski $\mathrm{P}$, et al.. Chronic stress, depression, and cortisol levels as risk indicators of elevated plaque and gingivitis levels in individuals aged 50 years and older. J Periodontol 2006;77:1008-1014.

5. Powell, LV, Leroux, BG, Persson, RE, Kiyak, HA. Factors associated with caries incidence in an elderly population. Community Dent Oral Epidemiol 1998;26:170-176.

6. Imazato S, Ikebe K, Nokubi T, Ebisu S, Walls AWG. Prevalence of root caries in a select population of older adults in Japan. J Oral Rehabil 2006;33:137-143.

7. Du M, Jiang H, Tai B, Zhou Y, Wu B, Bian Z. Root caries patterns and risk factors of middle-aged and elderly people in China. Community Dent Oral Epidemiol 2009;37:260-266.

8. Fure S. Ten-year cross-sectional and incidence study of coronal and root caries and some related factors in elderly Swedish individuals. Gerodontology 2004;21:130-140.

9. Anttila SS, Knuuttila ML, Sakki TK. Relationship of depressive symptoms to edentulousness, dental health, and dental health behavior. Acta Odontol Scand 2001;59:406-412.

10. Anttila SS, Knuuttila ML, Ylostalo P, Joukamaa M. Symptoms of depression and anxiety in relation to dental health behavior and selfperceived dental treatment need. Eur J Oral Sci 2006;114:109-114.

11. Griffin SO, Griffin PM, Swann JL, Zlobin N. Estimating rates of new root caries in older adults. J Dent Res 2004;83:634-638.

2. Burnner E, Marmot M. Social Organization, stress and health. Chapter 6. In: Social Determinants of Health. Oxford University Press, 2006. New York.

13. Johannsen A, Rylander G, Söder B, Asberg M. Dental plaque, gingival inflammation, and elevated levels of interleukin- 6 and cortisol in gingival crevicular fluid from women with stress-related depression and exhaustion. J Periodontol 2006;77:1403-1409.

14. Brazilian Institute of Geography and Statistics - IBGE [internet]. Brasilia (DF): Brazilian Institute of Geography and Statistics; 2000 [cited 2016 Aug 16]. Available from: http: www.ibge.gov.br/home

15. Hilgert JB, Hugo FN, de Sousa M da L, Bozzetti MC. Oral status and its association with obesity in Southern Brazilian older people.
Gerodontology 2009;26:46-52

16. Yesavage JÁ, Brink TL, Rose TL, Lum O, Huang V, Adey M. Development and validation of a geriatric depression screening scale: a preliminary report. J Psychiatr Res 1982;17:37-49.

17. Almeida $\mathrm{OP}, \mathrm{Alm}$ eida SA. Reliability of the Brazilian version of the Geriatric Depression Scale (GDS) short form. Arq Neuropsiquiatr 1999;57:421-426.

18. World Health Organization. Active ageing: a policy framework. Geneva: World Health Organization; 2002.

19. Navazesh M, Christensen CM. A comparison of whole mouth resting and stimulated salivary measurement procedures. J Dent Res 1982;61:1158-1162.

20. Holst $D$, Schüller AA, Aleksejuniene J, Eriksen HM. Caries in populations - a theoretical, causal approach. Eur J Oral Sci 2001;109:143-148

21. Hugo FN, Hilgert JB, Corso S, Padilha DM, Bozzetti MC, Bandeira DR, et al.. Association of chronic stress, depression symptoms and cortisol with low saliva flow in a sample of south-Brazilians aged 50 years and older. Gerodontology 2008;25:18-25.

22. Engeland $C G$, Hugo FN, Hilgert JB, Nascimento GG, Junges $R$, Lim HJ, et al.. Psychological distress and salivary secretory immunity. Brain Behav Immun 2016;52:11-17.

23. Hilgert JB, Hugo FN, Bandeira DR, Bozzetti MC. Stress, cortisol, and periodontitis in a population aged 50 years and over. J Dent Res 2006;85:324-328.

24. Phillips $A C$, Carroll D, Evans $P$, Jos $A B$, Clow $A$, Hucklebridge $F$, et al.. Stressful life events are associated with low secretion rates of immunoglobulin A in saliva in the middle aged and elderly. Brain, Behavior and Immunity 2006;20:191-197.

25. Hugo FN, Hilgert JB, De Souza MDLR, Cruy J. Depressive symptoms and untreated dental caries in older independently living south Brazilians. Caries Res 2012;46:376-384.

26. Aleksejuniene J, Holst D, Grytten Jl, Eriksen HM. Causal patterns of dental health in populations. An empirical approach. Caries Res 2002;36:233-240.

27. Sanchez-Garcia S, Reyes-Morales H, Juarez-Cedillo T, Espinel-Bermudez C; Solorzano-Santos F, Garcia-Pena C. A prediction model for root caries in an elderly population. Community Dent Oral Epidemiol 2011;39:44-52. 